\title{
Smartphone Addiction in Japanese College Students: Usefulness of the Japanese Version of the Smartphone Addiction Scale as a Screening Tool for a New Form of Internet Addiction
}

\author{
Masaru Tateno ${ }^{1,2} \bowtie$, Dai-Jin $\mathrm{Kim}^{3}$, Alan R. Teo ${ }^{4,5}$, Norbert Skokauskas ${ }^{6}$, \\ Anthony P. S. Guerrero ${ }^{7}$, and Takahiro A. Kato ${ }^{8}$ \\ ${ }^{1}$ Tokiwa Child Development Center, Tokiwa Hospital, Sapporo, Japan \\ ${ }^{2}$ Department of Neuropsychiatry, Sapporo Medical University, School of Medicine, Sapporo, Japan \\ ${ }^{3}$ Department of Psychiatry, Seoul St. Mary's Hospital, College of Medicine, The Catholic University of Korea, Seoul, Republic of Korea \\ ${ }^{4}$ Mental Health and Neurosciences Division, VA Portland Health Care System, Portland, USA \\ ${ }^{5}$ Department of Psychiatry, School of Medicine, Oregon Health \& Science University, Portland, USA \\ ${ }^{6}$ Centre for Child and Adolescent Mental Health and Child Protection Faculty of Medicine, Trondheim, Norway \\ ${ }^{7}$ Department of Psychiatry, Child and Adolescent Psychiatry Division, University of Hawai'i John A. Burns School of Medicine, Honolulu, USA \\ ${ }^{8}$ Department of Neuropsychiatry, Graduate School of Medical Sciences, Kyushu University, Fukuoka, Japan
}

\begin{abstract}
Objective Smartphone use is pervasive among youth in Japan, as with many other countries, and is associated with spending time online and on social media anywhere at any time. This study aimed to test a Japanese version of the Smartphone Addiction Scale-Short Version (SAS-SV) among Japanese college students.

Methods The subjects of this study were 602 college students in Japan. The study questionnaire consisted of questions about demographics (age, gender etc.), possession of a smartphone, internet use [length of internet use on weekdays and weekend, favorite social networking service (SNS) etc.], Young's Internet Addiction Test (IAT), and the Smartphone Addiction Scale-Short Version (SAS-SV) translated into Japanese.

Results There was a total of 573 respondents ( 180 male, 393 female) who completed the questionnaire (mean 19.3 \pm 1.3 years). LINE was the most popular social media platform (52.0\%) followed by Twitter (36.3\%). The overall Internet Addiction Test (IAT) score was $45.3 \pm 13.2$, with $4.5 \%$ classified as having severe addiction (IAT $\geq 70$ ). The mean SAS-SV scores were $24.4 \pm 10.0$ for males and $26.8 \pm 9.9$ for females. Based on proposed cutoff scores, $22.8 \%$ of males and $28.0 \%$ of females screened positive for smartphone addiction. The total scores of the SAS-SV and the IAT was correlated significantly.

Conclusion As the number of smartphone users becomes higher, problems related to smartphone use also become more serious. Our results suggest that the Japanese version of SAS-SV may assist in early detection of problematic use of smartphones.
\end{abstract}

Psychiatry Investig 2019;16(2):115-120

Key Words Behavioral addiction, Internet addiction, Internet gaming disorder, Internet use disorder, Pathological internet use.

\section{INTRODUCTION}

The internet has become an indispensable tool for our daily lives. The number of internet users has been increasing

Received: August 3, 2018 Revised: October 30, 2018

Accepted: December 25, 2018

$\triangle$ Correspondence: Masaru Tateno, MD, PhD

Tokiwa Child Development Center, Tokiwa Hospital, Tokiwa 3-1-6-1, Minami-ku, Sapporo 005-0853, Japan

Tel: +81-11-591-4711, Fax: +81-11-591-0922, E-mail: tatema@sapmed.ac.jp

(c) This is an Open Access article distributed under the terms of the Creative Commons Attribution Non-Commercial License (https://creativecommons.org/licenses/bync/4.0) which permits unrestricted non-commercial use, distribution, and reproduction in any medium, provided the original work is properly cited. year by year. In Japan, the number has reached over 100 million, and the penetration rate of the internet was reported as $83.5 \%$ in $2016 .{ }^{1}$ Because of widespread internet use, internet addiction has been a common and serious problem all over the world. Problematic internet use could cause various problems such as mental health issues, dietary problems, sleep deprivation, and academic failure. ${ }^{2-6}$ Many studies revealed a close relation between internet addiction and attention deficit hyperactivity disorder (ADHD) and suggested that individuals with developmental disorders are prone to internet addiction. ${ }^{7-10}$ Thus, early detection of and early intervention for internet-related problems are urgent tasks for mental health pro- 
viders.

The results of a nationwide survey conducted in 2016 by the Ministry of Internal Affairs and Communications of Japan demonstrated that, among 100.8 million internet users, $58.6 \%$ of them access the internet through desktop and/or laptop computers. ${ }^{1}$ It is notable that a similar percentage of individuals (57.9\%) use internet via smartphone. A smartphone has multiple functions as a mobile phone, palm-size computer, schedule notebook, game machine, camera, audio player, and video player. The convenient mobility of a smartphone could bind the users to the internet anytime and anywhere. All the rage around Pokémon GO in 2016 reflected widespread use of smartphone across all ages. ${ }^{11,12}$

Smartphone addiction is characterized by excessive and problematic smartphone use and clinical features of behavioral addiction: preoccupation, compulsive behavior, lack of control, functional impairment, withdrawal and tolerance. ${ }^{13-15}$ Smartphone addiction could be regarded as a new form of internet addiction because many youths have their smartphones with them all through the day and access the internet through the smartphone. In response to the increase of smartphone users, studies regarding smartphone addiction have been reported from various countries, mainly Asian and European countries. ${ }^{16-23}$ Several research groups developed questionnaires to screen for smartphone addiction, and some of them were translated into other languages. ${ }^{14,15,19,22-26}$ In proportion to the increasing awareness of smartphone related problems, more studies have been published. However, in Japan, a limited number of studies on smartphone addiction have been conducted thus far.

This study aimed to test the usefulness of the Japanese version of the Smartphone Addiction Scale (SAS) as a screening tool for a new form of internet addiction, to estimate the prevalence of smartphone addiction, and to investigate the correlation between smartphone addiction and internet addiction among Japanese college students.

\section{METHODS}

\section{Subjects}

The subjects of this study were 800 students of 5 colleges in Sapporo, Japan. Initially, research collaborators for data collection were recruited through the social network of the first author of this paper (M.T.). Then, five teachers of five colleges agreed to participate in this study voluntarily and distributed printed questionnaire sheets in the classrooms. All subjects participated in this study without any incentive provided by the study investigators.

\section{Study questionnaire}

The study questionnaire consisted of questions about demographics (age, gender etc.), possession of a smartphone, internet use [length of internet use on weekdays and weekend, favorite social networking service (SNS) etc.], Young's Internet Addiction Test (IAT), ${ }^{27,28}$ and the Smartphone Addiction Scale (SAS)-Short Version (SV) ${ }^{25}$ translated into Japanese.

The IAT consists of 20 questions regarding internet use that all begin with a sentence of "How often do you...": e.g. "How often do you find that you stay on-line longer than you intended?" Response choices are: 1=rarely, $2=$ occasionally, $3=$ frequently, $4=$ often, and $5=$ always. The IAT is used to assess the level of internet addiction and yields a score range of 20 to 100. In this study, we assessed the severity of internet problems based on the original cutoff points proposed by Young ${ }^{27}$ and in accordance with previous studies done in Japan. ${ }^{6,729}$ The scores on the IAT for each group in this study were: 20 to 39 points for the average user, 40 to 69 for possible addiction, and 70 to 100 points for severe addiction.

The Smartphone Addiction Scale (SAS) ${ }^{14}$ was developed as a self-report scale referring to the $\mathrm{K}$-scale, which has been commonly used as a screening tool for internet addiction in South Korea. ${ }^{30}$ The original SAS consisted of 33 questions assessing 6 factors regarding smartphone usage and using a six-point Likert scale (1: "strongly disagree" and 6: "strongly agree.") The short version of SAS (SAS-SV) was developed by shortening a standard SAS to make it easy to use as a screening tool in adolescents. ${ }^{25}$ The validity of the SAS-SV was confirmed by clinical interview by medical professionals for randomly selected subjects. Statistical analyses demonstrated that the AUC values for boys was 0.963 at the cut-off value of 31 (sensitivity value was 0.867 and specificity value was 0.893 ). For girls, the AUC value was 0.947 at the cut-off value of 33 (sensitivity value was 0.875 and specificity value was 0.886). The first author translated the SAS-SV in English into Japanese. Translation from English to Japanese was done in parallel by another bilingual co-author (TAK). A back translation was performed by a professional translator separately. Between the original version and the back translation, only subtle differences were found, and appropriate adjustments were made after a group discussion. One small modification was made by adding the term LINE, the most popular SNS application in Japan, after the term Facebook in the sentence of Q8 of the original version of SAS: "Constantly checking my smartphone so as not to miss conversations between other people on Twitter or Facebook."

\section{Statistical analysis}

Statistical analyses were performed by using StatFlex Ver.6 (Artec Inc., Osaka, Japan). Student t-test was used to com- 
pare the mean of two groups. To investigate the association between two factors, Pearson's correlation coefficient was calculated.

\section{Ethics}

The study protocol was approved by the ethics committee of Tokiwa Hospital prior to data collection (TKW-H28-0718). This study was conducted in accordance with the Declaration of Helsinki. The aim of this study was clearly stated on the first page of the anonymous questionnaire sheets. Response to the questionnaire was deemed indicative of consent.

\section{RESULTS}

We collected 602 out of 800 questionnaire sheets from the subjects (response rate was 75.3\%). There was a total of 573 respondents (180 male, 393 female) who completed questions regarding smartphone use. With regard to potential bias between completed $(n=573)$ and incompleted $(n=29)$ respondents, we did not find any statistically significant differences in terms of age ( $19.3 \pm 1.3$ vs. $19.8 \pm 1.9)$, gender ratio (M:F 180 : 393 vs. $10: 19)$ and mean IAT score (45.3 \pm 13.2 vs. $43.5 \pm 11.4)$. The results are summarized in Table 1.

The mean age was $19.3 \pm 1.3$ (males $19.3 \pm 1.4 /$ females $19.3 \pm$ 1.2 ) years. The mean length of internet use was $5.4 \pm 4.2$ (males $5.9 \pm 4.2$ /females $5.1 \pm 4.1$ ) hours on weekdays and $7.3 \pm 4.9$ (males $8.3 \pm 5.2 /$ females $6.8 \pm 4.7$ ) hours on weekend.

When we asked what the most favorable social networking service (SNSs) was among Facebook, Twitter, LINE [a free application for smartphones often used for (group) chatting] and others, in both male and female groups, LINE was the most popularly selected SNS application (48.9\% among males, 53.4\% among females, 52\% among all subjects). The second most popular was Twitter (35.6\% among males, 36.6\% among females, and $36.3 \%$ among all subjects).

The overall IAT score was $45.3 \pm 13.2$, with 193 respondents (33.7\%) classified as being average internet users (IAT $<40), 354(61.8 \%)$ classified as having possible addiction (IAT 40 to 69 ), and 26 (4.5\%) classified as having severe addiction (IAT 70 and higher). Following previous studies that regarded subjects with 70 and higher on the IAT as having addiction, ${ }^{6,727}$ the rate of IA was $4.5 \%$ in this study. Mean IAT scores and rates of average internet use, possible addiction and severe addiction in each gender were as follows: 46.2 $\pm 14.0,60$ (33.3\%), 112 (62.2\%), and 8 (4.4\%), respectively, among males;

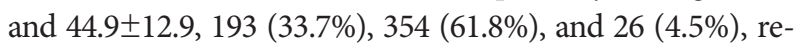
spectively, among females.

Concerning the smartphone addiction scale, mean SAS-SV scores were $26.1 \pm 10.0$ for all subjects, $24.4 \pm 10.0$ for males, and $26.8 \pm 9.9$ for females. A comparison of the mean IAT score and the mean SAS-SV score between male and female is shown in Figure 1. The higher SAS-SV score in female was consistent with previous studies. ${ }^{14,25}$

Kwon et al. ${ }^{25}$ proposed separate SAS-SV cutoff scores for males and females. Based on the proposed cutoff scores, in the male group, 41 out of 180 subjects (22.8\%) screened positive, and in female group, 110 out of 393 subjects (28.0\%) screened positive.

To investigate the association between the total scores of the SAS-SV and the IAT, Pearson's correlation coefficient was

Table 1. Summary of the results

\begin{tabular}{|c|c|c|c|c|}
\hline & Total $(\mathrm{N}=573)$ & Male $(\mathrm{N}=180)$ & Female $(\mathrm{N}=393)$ & $\mathrm{p}$ value \\
\hline Age & $19.3 \pm 1.3$ & $19.3 \pm 1.4$ & $19.3 \pm 1.2$ & 0.980 \\
\hline \multicolumn{5}{|l|}{ Internet use (hrs) } \\
\hline Weekdays & $5.4 \pm 4.2$ & $5.9 \pm 4.2$ & $5.1 \pm 4.1$ & 0.038 \\
\hline Weekend & $7.3 \pm 4.9$ & $8.3 \pm 5.2$ & $6.8 \pm 4.7$ & 0.002 \\
\hline Mean IAT score & $45.3 \pm 13.2$ & $46.2 \pm 14.0$ & $44.9 \pm 12.9$ & 0.294 \\
\hline IAT < $<0$ (\%) & $193(33.7)$ & $60(33.3)$ & $193(33.7)$ & \\
\hline $40 \leq \mathrm{IAT}<70(\%)$ & $354(61.8)$ & $112(62.2)$ & $354(61.8)$ & \\
\hline $\mathrm{IAT} \geq 70(\%)$ & $26(4.5)$ & $8(4.4)$ & $26(4.5)$ & \\
\hline \multicolumn{5}{|l|}{ SNS } \\
\hline Line (\%) & $298(52.0)$ & $88(48.9)$ & $210(53.4)$ & \\
\hline Twitter (\%) & $208(36.3)$ & $64(35.6)$ & $144(36.6)$ & \\
\hline Facebook (\%) & $10(1.7)$ & $3(1.7)$ & $7(1.8)$ & \\
\hline Others (\%) & $57(9.9)$ & 25 (13.9) & $32(8.1)$ & \\
\hline Mean SAS-SV score & $26.1 \pm 10.0$ & $24.4 \pm 10.0$ & $26.8 \pm 9.9$ & 0.008 \\
\hline SAS-SV positive (\%) & & $41(22.8)$ & $110(28.0)$ & \\
\hline
\end{tabular}

IAT: Internet Addiction Test, SNS: Social Networking Service, SAS-SV: Smartphone Addiction Scale-Short version 


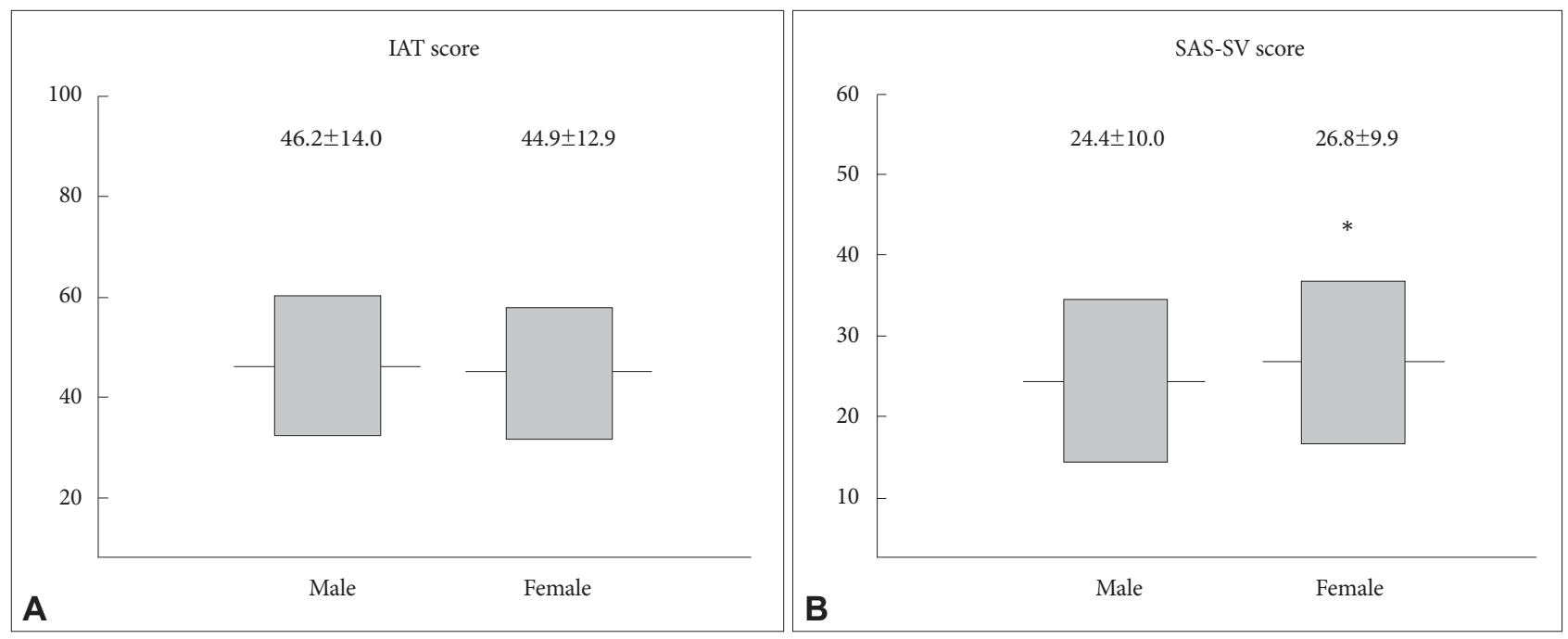

Figure 1. A comparison of the mean IAT score (A) and the mean SAS-SV score (B) between male and female groups. *statistically significant difference. IAT: Internet Addiction Test, SAS-SV: Smartphone Addiction Scale-Short Version.

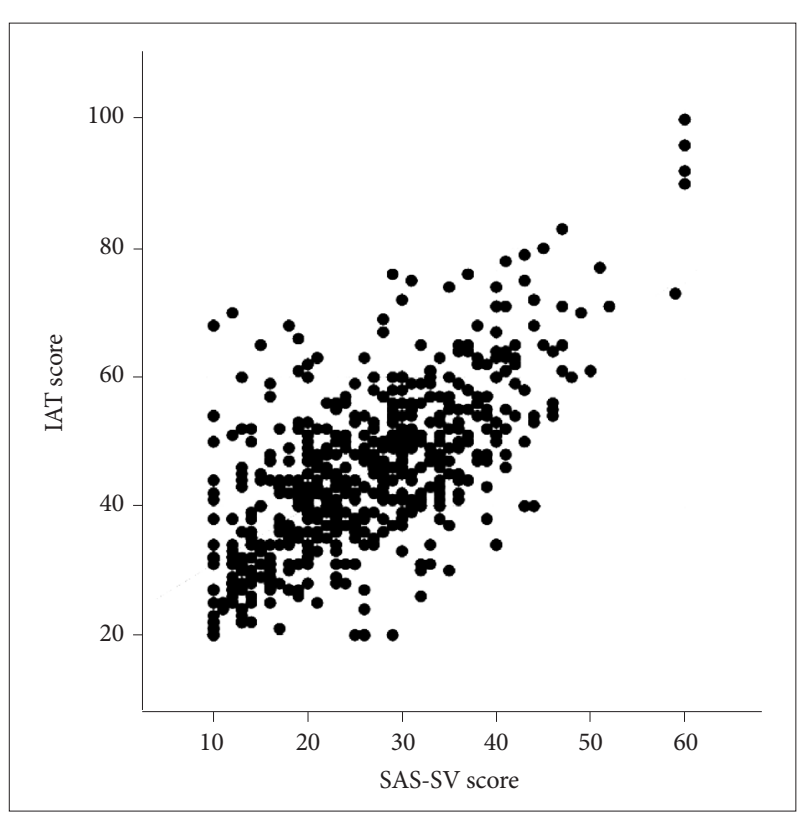

Figure 2. Pearson's Correlation Coefficient (IAT and SAS-SV). IAT: Internet Addiction Test, SAS-SV: Smartphone Addiction ScaleShort Version.

calculated, and a statistically significant relationship was revealed as shown in Figure $2(r=0.6744, p<0.0001)$. In regard to gender differences, correlation coefficient for male respondents was $r=0.6335$ and that for female was $r=0.7101$, respectively.

\section{DISCUSSION}

Japan's government conducted a nationwide survey on internet use and found that the highest rate of internet use was among 20 to 29 -year-olds (99.2\%) and that the second high- est rate was among 13 to 19 -year-olds $(98.4 \%) .{ }^{1}$ For each age group, the rate was higher than the rate from the previous year. These data suggest that children are starting to use internet at a lower age than before. An online survey $(n=759)$ conducted by a Japanese IT company named LINE revealed that about 70 percent of the teens access the internet exclusively through smartphone. ${ }^{31}$ As this survey was conducted through the internet by the IT company, there must be a significant sampling bias. However, because of smartphones' superb mobility and multifunction capability, a lot of teens have their smartphones with them all through the day. In other words, they are connected to the internet all day long.

As the number of internet users becomes higher, problems related to internet use become more serious. Nowadays, large number of internet users are suffering from internet addiction (IA), or internet overuse that causes functional impairment. ${ }^{4,28,32}$ A hundred studies reported that IA appears to be related to developmental disorders and/or mental health problems even in Japan. ${ }^{2,3,6,7}$ Similarly, as the number of smartphone users becomes higher, problems related to smartphone use also become more serious. Smartphone addiction could be observed in all ages. It is well-known that the group most susceptible to smartphone addiction is high school students, especially female students.

An article published in the Guardian, a UK-based newspaper circulated worldwide, attracted a great deal of attention with the shocking title "Our minds can be hijacked': the tech insiders who fear a smartphone dystopia." ${ }^{33}$ In his report, a former Google and Facebook engineer who created the "like" button on Facebook described it as "bright dings of pseudopleasure" and said that it would be a hollow message. In Japan, a similar situation could be observed among LINE users. 
In LINE, one can select, from a large number of options, funny illustrations (a so-called sticker or stamp in Japan), which could express the sender's feeling. Furthermore, LINE shows a "have been read" sign that appears on the screen of sender's smartphone once the message has been read by a receiver(s). By checking the sign, the sender can verify with certainty that the message has reached their friends. However, the pause after the "have been read" sign could imply various meanings. LINE users, including socially sensitive female adolescents, might feel ignored or disliked upon perceiving a pause between message sent and response. Thus, not only for enjoyable chatting with their peers, but also for insuring non-exclusion from the peer network, LINE users touch, swipe and tap their smartphones obsessively and compulsively. In severe cases, LINE users could tap their smartphone more than 1,000 times in a day. In view of this reality, and considering the term "Facebook addiction", ${ }^{34-37}$ we propose the term "LINE addiction" to describe subjects who overuse LINE and have a functional impairment.

Neither internet addiction (IA) nor smartphone addiction are listed as a psychiatric disorder in DSM-5. Only Internet Gaming Disorder is included in 'Conditions for Further Study', which suggests that the condition could be recognized as a psychiatric disorder in a future revision. The debate as to whether IA is a psychiatric disorder has lasted for about two decades since Young first proposed the concept of IA in 1998. ${ }^{27}$ Initially, Young proposed provisional diagnostic criteria for individuals with problematic internet use. Referring to the DSM-IV-TR criteria for substance dependence, she proposed the term 'internet addiction' and subsequently revised her definition of IA to more closely resemble an impulse-control disorder. The term IA has been often used to describe subjects with internet overuse accompanied by serious problems. Subsequently, the term 'smartphone addiction' was used to describe the individuals with problematic smartphone use.

Lin et al. ${ }^{38}$ proposed diagnostic criteria for smartphone addiction which consisted of six symptom criteria (Criteria A), four functional impairment criteria (Criteria B) and exclusion criteria (Criteria C). The proposed diagnostic criteria reflect four main components of addiction; excessive use, tolerance, withdrawal, and functional impairment. Furthermore, to increase the accuracy of diagnosis of smartphone addiction, besides clinical interview, Lin's group developed an application software to record data of smartphone use and incorporated the results into diagnostic criteria. ${ }^{39}$ In the future, the application on an individual's smartphone could record daily usage and might be utilized as a screening tool to detect smartphone addiction as early as possible.

There are several limitations in this study. The sample size was limited, and only college students were invited to par- ticipate. It is impossible to generalize our results because of a significant sampling bias. We did not ask about academic records, living conditions and economic status of respondents. None of our subjects underwent a clinical interview. The scales used in this study, such as the IAT and the SAS, have limited validity. We did not assess any psychiatric symptoms, such as depression, anxiety, and sleep disruptions, which are often observed as co-morbidities in patients with addictive disorders. We also did not assess for any formal diagnosis of a substance-related/addictive, obsessive-compulsive, or disruptive/impulse-control disorder.

To the best of our knowledge, this is the first study to investigate the usefulness of a Japanese version of the Smartphone Addiction Scale-Short Version (SAS-SV) in college students. Since the number of smartphone users has been increasing, and since the age when children start using the smartphone has been decreasing, the problem of smartphone addiction will become more and more serious in Japan. Medical professions should be aware of the seriousness of smartphone addiction, and the Japanese version of the SAS-SV could be used for early detection of smartphone use-related problems. Risk factors of smartphone addiction include younger age and co-morbid developmental disorders, and instructions for appropriate internet use could be a protective factor. Early intervention, enabled by early detection, could then prevent problematic smartphone use in children and the adolescents. We envision that further studies will focus on broadening the populations screened and correlating screening results with clinical findings and outcomes.

\section{Acknowledgments}

This work was partially supported by Grant-in-Aid for Scientific Research on (1) The Japan Agency for Medical Research and Development (AMED) (Syogaisya-Taisaku-Sogo-Kenkyu-Kaihatsu-Jigyo to M.T. \& T.A.K.) and (2) Innovative Areas "Will-Dynamics" of The Ministry of Education, Culture, Sports, Science, and Technology, Japan (JP16H06403 to T.A.K.).

\section{REFERENCES}

1. Information and Communications Bureau. Information and Information Communications Technology. Tokyo: Japan Ministry of Internal Affairs and Communications; 2017.

2. de Vries HT, Nakamae T, Fukui K, Denys D, Narumoto J. Problematic internet use and psychiatric co-morbidity in a population of Japanese adult psychiatric patients. BMC Psychiatry 2018;18:9.

3. Tateno M, Teo AR, Shirasaka T, Tayama M, Watabe M, Kato TA. Internet addiction and self-evaluated attention-deficit hyperactivity disorder traits among Japanese college students. Psychiatry Clin Neurosci 2016;70:567-572.

4. Vondrackova P, Gabrhelik R. Prevention of Internet addiction: A systematic review. J Behav Addict 2016;5:568-579.

5. Cerniglia L, Zoratto F, Cimino S, Laviola G, Ammaniti M, Adriani W. Internet Addiction in adolescence: Neurobiological, psychosocial and clinical issues. Neurosci Biobehav Rev 2017;76:174-184.

6. Kawabe K, Horiuchi F, Ochi M, Oka Y, Ueno S. Internet addiction: 
Prevalence and relation with mental states in adolescents. Psychiatry Clin Neurosci 2016;70:405-412.

7. So R, Makino K, Fujiwara M, Hirota T, Ohcho K, Ikeda S, et al. The prevalence of internet addiction among a Japanese adolescent psychiatric clinic sample with autism spectrum disorder and/or attentiondeficit hyperactivity disorder: a cross-sectional study. J Autism Dev Disord 2017:47:2217-2224.

8. Ho RC, Zhang MW, Tsang TY, Toh AH, Pan F, Lu Y, et al. The association between internet addiction and psychiatric co-morbidity: a metaanalysis. BMC Psychiatry 2014;14:183.

9. Wang BQ, Yao NQ, Zhou X, Liu J, Lv ZT. The association between attention deficit/hyperactivity disorder and internet addiction: a systematic review and meta-analysis. BMC Psychiatry 2017;17:260.

10. Jurgensen M, Kleinemeier E, Lux A, Steensma TD, Cohen-Kettenis PT, Hiort O, et al. Psychosexual development in adolescents and adults with disorders of sex development-results from the German clinical evaluation study. J Sex Med 2013;10:2703-2714.

11. Kato TA, Teo AR, Tateno M, Watabe M, Kubo H, Kanba S. Can Pokemon GO rescue shut-ins (hikikomori) from their isolated world? Psychiatry Clin Neurosci 2017;71:75-76.

12. Tateno M, Skokauskas N, Kato TA, Teo AR, Guerrero APS. New game software (Pokemon Go) may help youth with severe social withdrawal, hikikomori. Psychiatry Res 2016;246:848-849.

13. Elhai JD, Dvorak RD, Levine JC, Hall BJ. Problematic smartphone use: a conceptual overview and systematic review of relations with anxiety and depression psychopathology. J Affect Disord 2017;207:251-259.

14. Kwon M, Lee JY, Won WY, Park JW, Min JA, Hahn C, et al. Development and validation of a smartphone addiction scale (SAS). PLoS One 2013;8:e56936.

15. Lin YH, Chang LR, Lee YH, Tseng HW, Kuo TB, Chen SH. Development and validation of the Smartphone Addiction Inventory (SPAI). PLoS One 2014;9:e98312.

16. Matar Boumosleh J, Jaalouk D. Depression, anxiety, and smartphone addiction in university students-A cross sectional study. PLoS One 2017; 12:e0182239.

17. Aker S, Sahin MK, Sezgin S, Oguz G. Psychosocial Factors Affecting Smartphone Addiction in University Students. J Addict Nurs 2017;28: 215-219.

18. Chen B, Liu F, Ding S, Ying X, Wang L, Wen Y. Gender differences in factors associated with smartphone addiction: a cross-sectional study among medical college students. BMC Psychiatry 2017;17:341.

19. Khoury JM, de Freitas AAC, Roque MAV, Albuquerque MR, das Neves MCL, Garcia FD. Assessment of the accuracy of a new tool for the screening of smartphone addiction. PLoS One 2017;12:e0176924.

20. Davey S, Davey A. Assessment of smartphone addiction in Indian adolescents: a mixed method study by systematic-review and meta-analysis approach. Int J Prev Med 2014;5:1500-1511.

21. Haug S, Castro RP, Kwon M, Filler A, Kowatsch T, Schaub MP. Smartphone use and smartphone addiction among young people in Switzerland. J Behav Addict 2015;4:299-307.

22. Lopez-Fernandez O. Short version of the smartphone addiction scale adapted to Spanish and French: towards a cross-cultural research in problematic mobile phone use. Addict Behav 2017;64:275-280.

23. Ching SM, Yee A, Ramachandran V, Sazlly Lim SM, Wan Sulaiman WA, Foo YL, et al. Validation of a Malay Version of the smartphone addiction scale among medical students in Malaysia. PLoS One 2015;10: e0139337.

24. Lin YH, Pan YC, Lin SH, Chen SH. Development of short-form and screening cutoff point of the Smartphone Addiction Inventory (SPAISF). Int J Methods Psychiatr Res 2017;26.

25. Kwon M, Kim DJ, Cho H, Yang S. The smartphone addiction scale: development and validation of a short version for adolescents. PLoS One 2013;8:e83558.

26. Kim D, Lee Y, Lee J, Nam JK, Chung Y. Development of Korean smartphone addiction proneness scale for youth. PLoS One 2014;9:e97920.

27. Young KS. Caught in the Net: How to Recognize the Signs of Internet Addiction- and a Winning Strategy for Recovery. New York: Wiley; 1998.

28. Aboujaoude E. Problematic Internet use: an overview. World Psychiatry 2010;9:85-90.

29. Tateno M, Teo AR, Shiraishi M, Tayama M, Kawanishi C, Kato TA. Prevalence rate of internet addiction among Japanese college students: two cross-sectional studies and reconsideration of cut-off points of young's internet addiction test in Japan. Psychiatry Clin Neurosci 2018; 72:723-730.

30. Mak KK, Nam JK, Kim D, Aum N, Choi JS, Cheng C, et al. Cross-cultural adaptation and psychometric properties of the Korean Scale for Internet Addiction (K-Scale) in Japanese high school students. Psychiatry Res 2017;249:343-348.

31. LINE. A survey on the internet use environment. Tokyo: LINE Inc; 2017.

32. Jorgenson AG, Hsiao RC, Yen CF. Internet addiction and other behavioral addictions. Child Adolesc Psychiatr Clin N Am 2016;25:509-520.

33. Lewis P. 'Our Minds can be Hijacked': the Tech Insiders who Fear a Smartphone Dystopia. London: The Guardian, Guardian Media Group; 2017.

34. Ryan T, Chester A, Reece J, Xenos S. The uses and abuses of Facebook: a review of Facebook addiction. J Behav Addict 2014;3:133-148.

35. Brailovskaia J, Margraf J. Facebook Addiction Disorder (FAD) among German students-A longitudinal approach. PLoS One 2017;12:e0189719.

36. Casale S, Fioravanti G. Why narcissists are at risk for developing Facebook addiction: the need to be admired and the need to belong. Addict Behav 2018;76:312-318.

37. Andreassen CS, Torsheim T, Brunborg GS, Pallesen S. Development of a Facebook addiction scale. Psychol Rep 2012;110:501-517.

38. Lin YH, Chiang CL, Lin PH, Chang LR, Ko CH, Lee YH, et al. Proposed diagnostic criteria for smartphone addiction. PLoS One 2016;11: e0163010.

39. Lin YH, Lin PH, Chiang CL, Lee YH, Yang CCH, Kuo TBJ, et al. Incorporation of Mobile Application (App) measures into the diagnosis of smartphone addiction. J Clin Psychiatry 2017;78:866-872. 